\title{
Yabancı İşlemleri ile BIST100 Endeksi Arasındaki İlişki: ARDL Sınır Testi Yaklaşımı
}

\author{
Öz
}

Erkan USTAOĞLU*

Yabancıların BIST'te yaptıkları alım ve satım ișlemlerinin BIST'teki toplam payı \%50 seviyelerine gelmiştir. Yabancıların BIST'teki paylarının bu denli yüksek olması yaptıkları işlemlerin borsa üzerindeki etkilerini de artırmaktadır. Bu noktadan hareketle çalışmada yabancı yatırımcıların BIST'te yaptıkları alım ve satım işlemlerinin BIST100 endeksine olası kısa ve uzun dönemetkilerinin tespit edilmesi amaçlanmaktadır. Çalışmada 2009:09-2020:03 dönemi aylık veriler kullanılarak yabancı yatırımcıların BIST'te yaptıkları alım ve satım işlem hacimleri ile BIST100 endeksi arasındaki ilişkiler ARDL (Autoregressive Distibuted Lag) sınır testi ile araştırılmıştır. Çalışmanın sonucunda, yabancı yatırımcıların BIST'te yaptıkları hisse senedi alış ve satış işlemleri ile BIST100 endeksi arasında uzun dönemli bir eşbütünleşme ilişkisi olduğu saptanmıștır. Yabancı yatırımcıların BIST’te yaptıkları hisse senedi alışları hem kısa hem de uzun dönemde BIST100 endeksini artırırken, yabancı yatırımcıların BIST'te yaptıkları hisse senedi satışları ise BIST100 endeksini azaltmaktadır. Ancak uzun dönemde BIST100 endeksi, yabancı yatırımcının hisse senedi satışlarından daha fazla etkilenmektedir.

Anahtar Kelimeler: Yabancı Yatırımc1, Yabancı Yatırım, BIST100, ARDL Sınır Testi.

\section{The Relationship between Foreign Transactions and BIST100 Index: An ARDL Bounds Testing Approach}

\section{Abstract}

The total share of foreigners' purchase and sale transactions in BIST has reached 50\%. The high share of foreigners in BIST increases the effects of their transactions on the stock market. From this point of view, the study aims to determine the possible short and long-term effects of the purchase and sale transactions made by foreign investors in BIST on the BIST100 index. In the study, the relationships between the trading volumes of foreign investors in BIST and the BIST100 index were investigated by using ARDL (Autoregressive Distibuted Lag) boundary test by using monthly data for the period 2009: 09-2020: 03. As a result of the study, it has been determined that there is a long-term cointegration relationship between the stock purchase and sales of foreign investors in BIST and the BIST100 index. While foreign investors' purchases of stocks in BIST increase the BIST100 index in both the short and long term, the stocks sales made by foreign investors in BIST decrease the BIST100 index. However, in the long run, the BIST 100 index is affected more by foreign investors' stock sales.

Keywords: Foreign Investor, Foreign Investment, BIST100, ARDL Boundary Test.

Geliş/Received: 15.09 .2020

Kabul/Accepted: 22. 12. 2020

* Bu çalışma, insanlardan veri ve örnek toplamayı gerektiren, anket, inceleme, alan çalışması ve deney içeren araştırmalar 'kapsamına girmediğinden etik kurul onay belgesi gerektirmemektedir.

\footnotetext{
Öğr.Gör.Dr. Hitit Üniversitesi, Sosyal Bilimler Meslek Yüksekokulu, Yönetim ve Organizasyon Bölümü, ustaogluerkan@hotmail.com, D/0000-0002-4932-356X.

(Makale türü: Araştırma Makalesi)
} 


\section{Erkan USTAOĞLU}

\section{Yabanıı İşlemleri ile BIST100 Endeksi Arasındaki İlişki: ARDL Sınır Testi Yaklaşımı}

\section{Giriş}

Uluslararası sermaye hareketlerinin önündeki hukuki engellerin gevşetilmesi ile birlikte sermayenin yer değişikliğinde ciddi artışlar yaşanmıştır. Hukuki düzenlemelere ek olarak yaşanan finansal liberalizasyon, teknolojik gelişmeler ve küreselleşme olgusu beraberinde yerel hisse senedi piyasalarını etkilemiş ve yabancı yatırımcıların yerel hisse senedi piyasalarında yaptıkları işlemleri artırmıştır (Gümüş, 2010). 1990'lardan önce yatırımcıların portföyleri yerli menkul kıymetlerden oluşmaktaydı. Ancak 1990'lardan sonra uluslararası portföy çeşitlendirme etkilerinden faydalanmak isteyen yabancı yatırımcılar, yatırımlarını diğer ülkelere aktararak portföylerindeki yabancı menkul kıymetlerin ağırlıklarını artırmıştır (Garg ve Dua, 2014; Okuyan ve Erbaykal, 2011). Bu durum özellikle gelişmekte olan piyasalarda yatırımcı türlerinde değişikliğe yol açmıştır.

Türkiye'de 1985 yllında kurulan ve 1989 yllında finansal liberalizasyon hareketiyle birlikte yabancılara açılan Borsa İstanbul'da (BIST)yabancı işlemlerindegenel olarak artış yaşanmaktadır.2010-2019 yılları itibari ile BIST’te yaşanan artış trendi Şekil 1 ve Şekil 2'de gösterilmiştir.

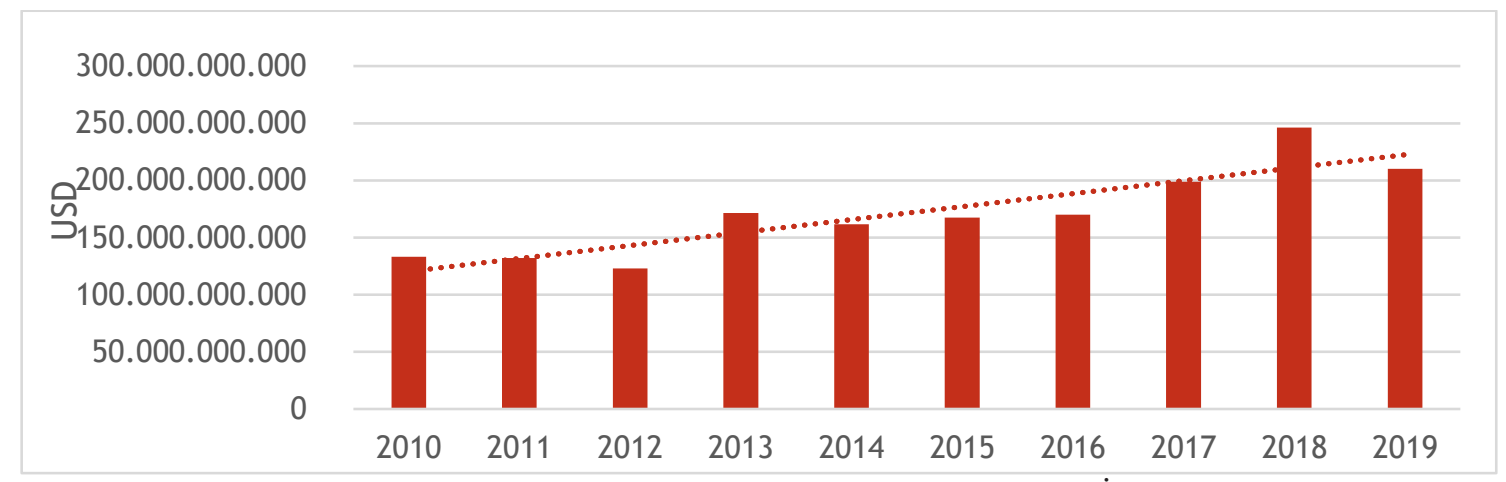

Şekil 1.2010-2019 Döneminde BIST’te Gerçekleșen Yabancı İşlem Hacmi

Kaynakça: Borsa İstanbul'dan Elde Edilen Veriler ile Yazar Tarafindan Oluşturuldu (https://datastore.borsaistanbul.com/.Erișim tarihi: 01.05.2020)

Şekil 1'de 2010-2019 yılları arasında BIST'te gerçekleşen yabancı işlem hacmi yer almaktadır. Şekil 1'e göre 2010-2019 yılları arasında BIST'te gerçekleşen yabancı işlem hacmi genel olarak bir artış trendine sahiptir. BIST'te gerçekleşen yabancı işlem hacmi 2018 yılında yaklaşık 246 milyar dolar ile rekor seviyeye ulaşmıştır. 2019 yılında gerçekleşen yabancı işlem hacmi ise yaklaşık 210 milyar dolar olarak gerçekleşmiştir. Şekil 2'de 2009:10-2020:03 dönemi arasında yabancı işlem hacminin BIST toplam işlem hacmi içindeki payı gösterilmiştir. 


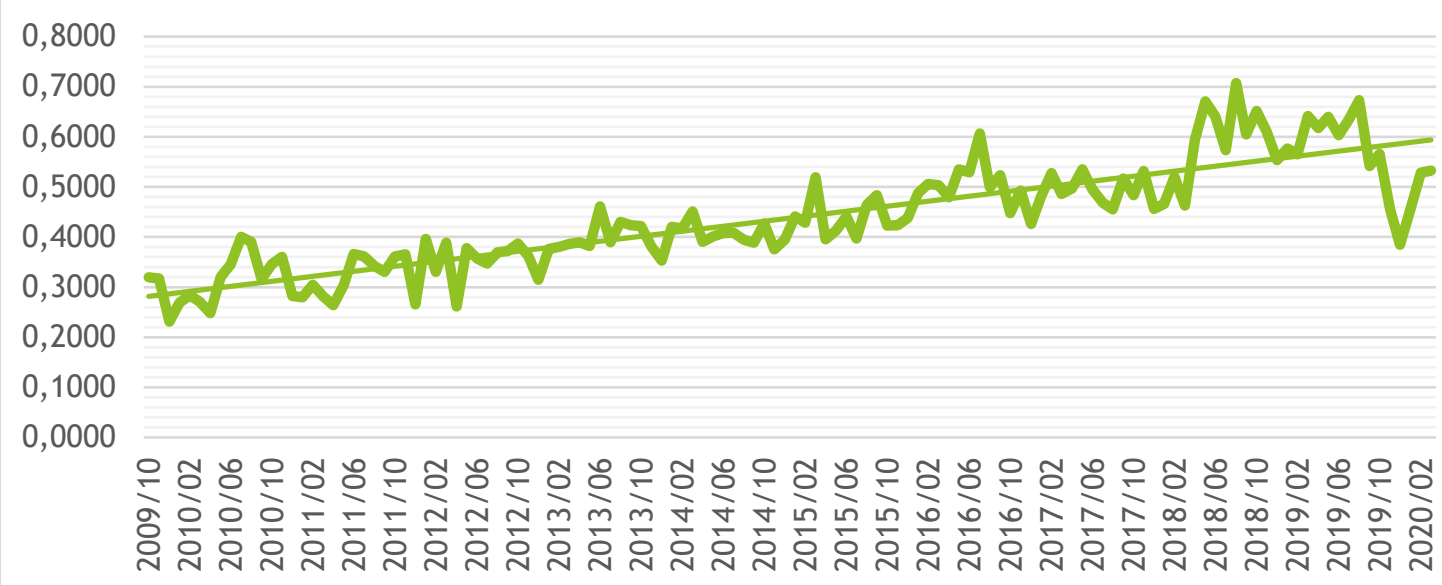

Şekil 2. 2009:10-2020:03 Döneminde Yabancı İşlem Hacminin BIST Toplam İşlem Hacmi İçindeki Payı

Kaynakça: Borsa İstanbul'dan Elde Edilen Veriler ile Yazar Tarafindan Oluşturuldu (https://datastore.borsaistanbul.com/.Erișim tarihi: 01.05.2020)

Şekil 2'ye göre BIST'te yabancı işlemlerinin toplam işlem hacmiiçerisindeki payı, aylık olarak dalgalı seyretmesinerağmen yıllık olarak artış trendine sahiptir. Şekil 2'de görüldüğü üzere BIST’te yabancı işlemlerinin toplam işlemler içindeki payı 2009 Aralık ayında \%24,78 ile en az seviyede iken 2018 Ağustos ayında rekor bir seviyeye ile \%70,71'e ulaşmıştır.Şekil 3'te ise 2009:10-2020:03 dönemindeBIST’teki net yabancı işlemleri gösterilmiştir.Şekil 3'te görüleceği üzere 2020 yılı ilk üç ayı net yabancı işlemleri negatif gerçekleşmiştir. Net yabancı işlemleri Haziran 2013'te yaklaşık -1,2 milyar dolarile en düşük seviyede iken, Mart 2012'de net yabanc1 işlemleri 1,8 milyar dolar ile en üst seviyededir.

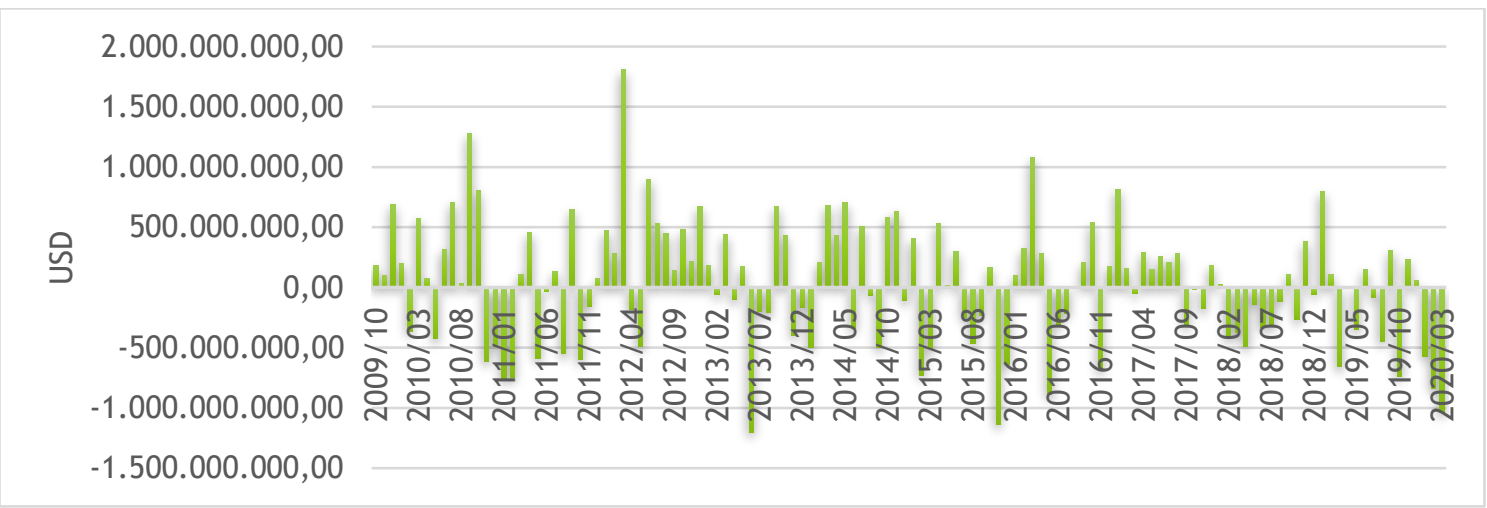

Şekil 3. 2009:10-2020:03 Döneminde BIST’teki Net Yabancı İşlemleri

Kaynakça: Borsa İstanbul'dan Elde Edilen Veriler ile Yazar Tarafından Oluşturuldu (https://datastore.borsaistanbul.com/.Erișim tarihi: 01.05.2020)

Yabancı portföy yatırımı olarak ülkeye giren yabancı sermaye, ülkede sermaye birikimini artırarak ekonomik büyümeyi artırır. Ancak bu tarz yatırımların etkilerini sadece ekonomik büyüme ile sınırlandırmak doğru değildir.Özellikle Türkiye'de yabancı yatırımcılar, hisse senedi piyasalarındaki varlıkların yaklaşık yarısını elinde bulundurduklarından ve yaptıkları işlem hacminin fazlalığından dolayı bu yatırımların borsaya etkisi muhakkak bulunmaktadır. Bu noktadan hareketle çalışmanın temel amacı,yabancı yatırımcıların BIST’te yaptıkları alım ve 


\section{Erkan USTAOĞLU}

Yabancı İşlemleri ile BIST100 Endeksi Arasındaki İlişki: ARDL Sınır Testi Yaklaşımı

satım işlemlerinin BIST100 endeksine olas1 kısa ve uzun dönem etkileriniortaya koymaktır.Literatürdeki ilgili çalışmaların eksikliği göz önüne alındığında, çalışma literatüre iki temel katkı sağlamaktadır. İlk olarak diğer çalışmalardan farklı olarak yabancı işlemleri, alım ve satım olarak ayrı ayrı değerlendirilmiştir. İlgili literatür incelendiğinde yapılan çalışmaların bir kısmı yabancı işlem hacminin BIST’teki etkileri üzerinde durmuştur (Akar, 2008; Doğukanlı ve Çetenak, 2008; Okuyan ve Erbaykal, 2011). Literatürün diğer bir kısmı ise yabancı yatırım girişlerinin endeks üzerindeki etkilerine odaklanmıştır (Baklacı, 2009; İbicioğlu, 2012; Kesik, Canakcı ve Tunali, 2016; Şenol ve Koç, 2018). Yabancı işlemlerinin alım ve satım olarak ayrı ayrı değerlendirmek bu işlemlerin BIST üzerindeki etkileri net görebilmek adına önemlidir. Çünkü uzun dönemde hisse senedi fiyatları yabancı yatırımcıların alımlarından mı yoksa satımlarından $\mathrm{m}$ daha fazla etkilendiğinin tespit edilmesi, politika yapıcıların uygulayacakları politikaların farklılığı konusunda önemli bir yol göstergesi olacaktır. Literatüre olan diğer bir katkısı kullanılan yöntem bakımından olmuştur. Literatürde yabancı işlemleriyle endeks getirileri arasındaki ilişkiler incelenirken VAR yönteminden ve Granger nedensellik testinden sıklıkla yararlanılmıştır (Doğukanlı ve Çetenak, 2008; Baklacı, 2009; Gümüş, 2010; İskenderoğlu ve Karadeniz, 2011; İbicioğlu, 2012; Kesik, Canakcı ve Tunali, 2016; Şenol ve Koç, 2018). Çalışmamızda ise yabancı işlemleri ile BIST endeksi arasındaki ilişkiler ARDL sınır testi kullanılarak araştırılmıştır.

Çalışmanın devamı şu şekilde organize edilmiştir; ikinci bölümde ilgili literatür taramasına yer verilmiş, üçüncü bölümde çalışmanın veri seti ve ekonometrik yöntemine değinilmiştir. Dördüncü bölümde çalışmaya ait bulgulara yer verilmiş olup bu bölümü sonuç kısmı takip etmektedir.

\section{Literatür}

Yabancı yatırımcıların hisse senedi piyasalarına olan etkileri birçok araştırmacı tarafından farklı ülke ve dönemler itibari ile araştırılmıştır. Bu çalışmalardan biri olan Clark ve Berko (1997), 1989-1996 yıları arasında Meksika'dahisse senedi getirisi ile yabancı işlemleri arasındaki ilişkiyi en küçük kareler yöntemi ile araştırmış ve yabancı yatırımcıların gerçekleştirdiği alımların hisse senedi fiyatlarını artırdığını ve portföy yatırımlarındaki \%1'lik bir artışınhisse senedi fiyatlarında \%13'lük bir artışa sebep olduğunu tespit etmiştir. Benzer şekilde Froot, Connell ve Seasholes (2001), 1994-1998 yılları arasında günlük veriler kullanarak 44 ülkede hisse senedi getirileri ile yabancı portföy yatırımları arasındaki ilişkiyi araştırmaktadır. Çalışmanın sonuçlarına göre, yabancı portföy yatırımları hisse senedi getirilerini pozitif etkilemektedir ve bu etki gelişmekte olan piyasalarda istatistiksel olarak anlamlıdır. Bir başka çalışma Richards (2005) tarafından yapılmıştır. 1999:01-2002:09 dönemi günlük veriler kullanarak gelişmekte olan altı Asya ülkesinde yabancı yatırımcıların hisse senedi alım ve satım 
işlemleri ile endeks getirisi arasındaki ilişkiyi VAR metodu ile araştıran Richards (2005), yabancıların hisse senedi alış işlemlerinin endeks getirisini pozitif etkilediğini tespit etmiştir. Günlük verilerle yapılan bir başka çalışmayıgerçekleştiren Samarakoon (2009), 03.01.199231.12.2004 dönemi Sri Lanka hisse senedi piyasasında yatırımcı çeşitlerinin etkilerini VAR metodu ile araştırmaktadır. Çalışmanın sonuçlarına göre, hem bireysel hem de kurumsal olarak yerli ve yabancı yatırımcıların yaptıkları alım ve satım işlemleri, geçmiş dönem hisse senedi getirileri ile pozitif ilişkilidir ancak bu etki kriz dönemlerinde negatif olmaktadır. Ayrıca yabancı kurumsal alıcıların hisse senedi getirilerini etkilemediği tespit edilmiştir. Günlük verilerin kullanıldığı bir diğer çalışmayı gerçekleştiren Gültekin ve Umutlu (2016) ise, 2004-2010 yılları arasında yabancı yatırımcının Güney Kore Borsası üzerine etkilerini VAR metodu ile araştırmaktadır. Çalışmanın sonuçlarına göre net yabancı alımları ile geçmiş endeks getirileri arasında pozitif bir ilişki olduğu saptanmıştır. 1990-2009 dönemi Nijerya'da hisse senedi piyasası getirileri ile yabancı portföy yatırımları arasındaki ilişkiyi araştıran Anayochukwu (2012), yabancı portföy yatırımlarının borsa getirisi üzerinde pozitif bir etkiye sahip olduğunu tespit etmiştir. Haider, Khan, Saddique ve Hashmi (2017), 2007:Q1-2015:Q4 dönemi çeyreklik veriler kullanarak Çin'de borsa performansı ve enflasyon ile yabancı portföy yatırımları arasındaki ilişkileri ARDL sınır testi ile araştırmıştır. Çalışmanın sonuçlarına göre, yabancı portföy yatırımları borsa performansını pozitif etkilemektedir. Feng, Lin ve Wang (2017), 1997:062013:06 dönemi aylık verilerini kullanarak Çin'de yabancı yatırımların hisse senedi ve konut fiyatlarına etkilerini VAR metodu ile araştırmaktadır. Çalışmada yabancı portföy girişlerinin, hisse senedi ve konut fiyatlarını önemli ölçüde arttırdığ ve bu etkinin 1-2 ay kadar daha devam ettiği tespit edilmiştir.

Türkiye'de yabancı yatırımcıların hisse senedi piyasasına olan etkilerini araştıran Karataş, Dönmez ve Kiraz (2004), yabancı yatırımcıların İstanbul Menkul Kıymetler Borsası (IMKB) 30 endeksine olan etkilerini incelemiştir. Çalışmada yabancı alımları endeks getirisini pozitif etkilerken, yabancı satışlarının endeks getirisini negatif etkilediği tespit edilmiştir. $\mathrm{Bu}$ konuda yapılmış bir diğer çalışma Akar’a (2008) aittir. 1997:01-2005:09 dönemi aylık verilerini kullanarak net yabancı işlem hacmi ile hisse senedi fiyatları arasındaki ilişkiyi Granger nedensellik testi ve ARDL sınır testi ile araştıran Akar (2008), hisse senedi fiyatları ile yabancı işlem hacmi arasında uzun dönemli anlamlı bir ilişki bulunmadığını ancak kısa dönemli pozitif bir ilişki olduğunu tespit etmiş̦tir. Akar'ın (2008) aksine Okuyan ve Erbaykal (2011), 1997:012009:12 dönemi aylık verilerinkullanıldığı çalışmada, hisse senedi getirisi ile yabancı işlem hacmi arasında uzun dönemli pozitif bir ilişki olmasına rağmen kısa dönemde anlamlı bir ilişki olmadığını tespit etmiştir. 


\section{Erkan USTAOĞLU}

Yabancı İşlemleri ile BIST100 Endeksi Arasındaki İlişki: ARDL Sınır Testi Yaklaşımı

Doğukanlı ve Çetenak (2008), 1997:02-2006:12 dönemi aylık veriler ile hisse senedi getirisi ile yabancı portföy yatırımları arasındaki ilişkileri VAR metodu ve Granger nedensellik testi ile araştırmaktadır. Çalışmada, hisse senedi getirisinden yabancı portföy yatırımlarına doğru tek yönlü nedensel bir ilişki olduğu saptanmıştır. Baklacı (2009) çalışmasında yabancı yatırımcı işlemleri ile hisse senedi getirisi arasındaki ilişkiyi VAR metodu ile incelemiştir. Çalışmada 1997:01-2007:12 dönemi aylık veriler kullanılmıştır. Çalışmanın sonucunda, hisse senedi getirisi ile yabancı işlemleri arasında güçlü ve karşılıklı etkileşim olduğu tespit edilmiştir. Yabancı portföy yatırımlarının IMKB üzerine etkilerini Engle-Granger eşbütünleşme ve Granger nedensellik testleri ile araştıran Gümüş (2010) ise, yabancı yatırımcı işlemleri ile IMKB100 endeksi arasında uzun dönemli ilişki tespit etmiş ve yabancı yatırımcıların IMKB'de yaptıkları alımların endeksi pozitif etkilediğini, yaptıkları satışların ise negatif etkilediğini tespit etmiştir. Günlük verilerin kullanıldığı bir diğer çalışma İskenderoğlu ve Karadeniz (2011) tarafından yapılmıştır. Çalışmada, 05.01.2009-31.05.2011 dönemi arasında yabancı portföy yatırımlarının IMKB100 endeks getirisi üzerindeki etkileri Granger nedensellik testi ile araştırılmıştır. Çalışmanın sonucunda, IMKB100 endeksi getirisinin yabancı portföy yatırımlarının piyasa değerini tek yönlü olarak etkilediği tespit edilmiştir. Yurtdışı yerleşiklerin hisse senedi alımlarının etkilerini sektörel endeksler bazında inceleyen İbicioğlu (2012), yabancı yatırımcıların hisse senedi yatırımlarının incelenen endeksler üzerinde etkili olduğunu tespit etmiştir. Kesik, Canakcı ve Tunali (2016), 07.01.2005- 02.01.2015 dönemi haftalık veriler kullanarak yabancı portföy yatırımlarının BIST100 endeksindeki dalgalanmalar üzerine etkilerini VAR metodu ve Granger nedensellik testi ile araştırmaktadır. Çalışmanın sonuçlarına göre, yabancı yatırımcıların hisse senedi alımları BIST100 endeksini artırmaktadır. Benzer şekilde Şenol ve Koç (2018), 2006:Q12016:Q4 dönemi çeyreklik veriler ile yabancı portföy girişleri, BIST ve makro ekonomik faktörler arasındaki ilişkiyi VAR metodu ile araştırmaktadır. Çalışmanın sonucunda yabancı portföy yatırımlarında meydana gelen değişimlerin BIST'i etkilediği tespit edilmiştir.

\section{Araştırmanın Yöntemi ve Veri Seti}

Çalışmanın temel amacı yabancı yatırımcıların BIST’te yaptıkları alım ve satım işlemleri ile BIST100 endeksi arasında olası kısa ve uzun dönemli ilişkilerin araştııılmasıdır. Bu amaçlaçalışmada, 2009:09-2020:03 dönemi aylık veriler kullanılarakyabancı yatırımcıların BIST’te yaptıkları alım ve satım işlem hacimleri ile BIST100 endeksi kapanış fiyatları kullanılmıştır. Çalışmada kullanılan tüm veriler Borsa İstanbul'dan elde edilmiştir. Çalışmada kullanılan tüm değişkenlerin logaritmik formları ve dolar cinsinden değerleri kullanılmıştır. Veriler ile ilgili kısaltmalar ve bu verilerin elde edildiği kaynaklar Tablo 1'de özetlenmiştir. 
Tablo 1.Çalışmada Kullanılan Değişkenler ve Kaynakları

\begin{tabular}{|l|l|l|}
\hline \multicolumn{1}{|c|}{ Değişkenler } & \multicolumn{1}{|c|}{ Açıklama } & \multicolumn{1}{c|}{ Kaynak } \\
\hline LNBIST & BIST100 endeksi kapanış fiyatları (\$) & Borsa İstanbul \\
\hline LNALIM & Yabancıların BIST'te yaptıkları alımlar (\$) & Borsa İstanbul \\
\hline LNSATIM & Yabancıların BIST’te yaptıkları satımlar (\$) & Borsa İstanbul \\
\hline
\end{tabular}

\section{ARDL Sinır Testi}

Ampirik çalışmalarda uzun dönemli ilişkileri araştırmak için genellikle Engle ve Granger (1987) ve Johansen (1998) ve Johansen-Juselius'un (1990) geliştirdikleri eşbütünleşme yöntemleri kullanılır. Engle ve Granger (1987) eşbütünleşme testi iki değişken arasındaki ilişkileri incelerken, Johansen eşbütünleşme testi, ikiden fazla değişken arasındaki uzun dönemli ilişkiyi araştırır. Ancak bu testlerin kullanılabilmesi için tüm değişkenlerin birinci farkta durağan olmaları [I(1)] gerekmektedir. Ancak Pesaran, Shin ve Smith (2001) tarafından geliştirilen ARDL sınır testinde bu ön koşul aranmamaktadır. ARDL sınır testinde değişkenlerin düzeyde durağan olduğunda, farkta durağan olduğunda veya bazılarının düzeyde [I(0)] bazılarının birinci farkta [I(1)] durağan olduğu durumlarda kullanılmaktadır (Narayan ve Narayan, 2005; Pesaran ve diğer., 2001). Ancak ikinci farkta durağan [I(2)] olan değişken varsa ARDL testi kullanılamamaktadır (Pesaran ve diğer., 2001). Ayrıca ARDL sınır testinde kullanılan kısıtsız hata düzeltme modeli klasik eşbütünleşme testlerine göre daha güvenilir sonuçlar vermektedir. ARDL sınır testinin klasik eşbütünleşme testlerine göre diğer bir avantajı ise küçük örneklemlerde daha iyi sonuçlar vermesidir (Narayan ve Narayan, 2005).

ARDL sınır testi üç aşamalı bir testtir. İlk olarak değişkenler arası eşbütünleşmenin varlı̆̆ 1 araştırılır. Değişkenler arası eşbütünleşmenin varlığı durumda ikinci aşamaya geçilir. İkinci olarak değişkenler arası uzun dönem katsayıları elde edilir. Son olarak değişkenler arası kısa dönem katsayıları elde edilir (Narayan ve Smyth, 2006). ARDL sınır testinin ilk aşamasında kullanılan üç değişkenli hata düzeltme modelinin çalışmamıza uyarlanmış hali:

$$
\begin{aligned}
\Delta L N B I S T=\beta_{0} & +\sum_{i=1}^{k} \beta_{1 i} \Delta \text { LNBIST }_{t-i}+\sum_{i=0}^{k} \beta_{2 i} \Delta \text { LNALIM }_{t-i}+\sum_{i=0}^{k} \beta_{3 i} \text { LLNSATIM }_{t-i} \\
& +\beta_{4 i} \text { LNBIST }_{t-1}+\beta_{5 i} \text { LNALIM }_{t-1}+\beta_{6 i} \text { LNSATIM }_{t-1}+\varepsilon_{t}
\end{aligned}
$$

denklem (1)'deki gibidir. Denklemde $\Delta$ değişkenlerin birinci farklarını, $\mathrm{k}$ ise uygun gecikme sayısını ifade etmektedir. k ile gösterilen uygun gecikme uzunluğunun belirlenmesinde Akaike (AIC), Schwarz (SC), Hannan-Quinn (HQ) ve benzeri bilgi kriterlerinden faydalanılır. Burada k değeri için en küçük bilgi kriterini sağlayan ve modelde otokorelasyon problemine sahip olmayan gecikme, model için uygun gecikmedir. Denklem (1)'de olası eşbütünleşmenin varlığı F istatistiği yardımı ile araştırılmaktadır. Denklem (1)'de olası eşbütünleşmenin sınanması için kurulan hipotezler şu şekildedir:

$H_{0}: \beta_{3}=\beta_{4}=\beta_{5}=0$ (Değișkenler arası eşbütünleșme yoktur.) 


\section{Erkan USTAOĞLU}

Yabancı İşlemleri ile BIST100 Endeksi Arasındaki İlişki: ARDL Sınır Testi Yaklaşımı

$H_{1}: \beta_{3} \neq 0, \beta_{4} \neq 0, \beta_{5} \neq 0$ (Değişkenler arası eşbütünleşme vardır.)

Denklem 1'de hesaplanan F istatistiği Pesaran ve diğer. (2001) çalışmasında belirtilen kritik değerle karşılaştırılır. Eğer hesaplanan F istatistiği Pesaran ve diğer. çalışmasında belirtilen alt ve üst kritik değerden büyük ise $H_{0}$ reddedilir ve değişkenler arası eşbütünleşme olduğuna karar verilir. F istatistiği alt ve üst kritik değerin altında olduğunda $H_{0}$ kabul edilir ve değişkenler arası eşbütünleşme olmadığı sonucu çıkarılır. Ancak F istatistiği alt ve üst kritik değerin arasında yer aldığında eşbütünleşme ile ilgili net bir karara varılamaz (Pesaran ve diğer., 2001).

Denklem (1) için hesaplanan F istatistiği kritik değerlerin üzerinde olduğunda, ARDL sınır testinin iki ve üçüncü aşaması olan uzun ve kısa dönemli ilişkilerin tespitine geçilebilir. Çalışmamızda değişkenlerin uzun dönemli ilişkisinin varlığ için oluşturulan ARDL modeli:

$L N B I S T=\beta_{0}+\sum_{i=1}^{a} \beta_{1 i} \Delta$ LNBIST $_{t-i}+\sum_{i=0}^{b} \beta_{2 i} \Delta$ LNALIM $_{t-i}+\sum_{i=0}^{c} \beta_{3 i} \Delta$ LNSATIM $_{t-i}+\varepsilon_{t}$

denklem (2)'deki gibidir. Çalışmamızda değişkenler arası kısa dönemli ilişkinin varlığı için oluşturulan ARDL hata düzeltme modeli ise:

$$
\begin{aligned}
\text { LNBIST }=\beta_{0}+ & \sum_{i=1}^{a} \beta_{1 i} \Delta \text { LNBIST }_{t-i}+\sum_{i=0}^{b} \beta_{2 i} \Delta \text { LNALIM }_{t-i}+\sum_{i=0}^{c} \beta_{3 i} \Delta \text { LNSATIM }_{t-i}+\alpha E C T_{t-1} \\
& +\varepsilon_{t}
\end{aligned}
$$

denklem (3)'teki gibidir. Denklem 3'teki ECT hata düzeltme terimidir. ECT teriminin katsayısı $(\alpha),-1$ ile 0 arasında ve istatistiksel olarak anlamlı olması beklenmektedir. Bu katsayı kısa dönemde oluşacak bir sapmadan ne kadar zaman sonra dengeye geleceğini göstermektedir. $\alpha$, 1'e yakın bir değer aldığında kısa dönemdeki sapmaların daha hızlı dengeye geldiğini, 0'a yakın bir değer aldığında kısa dönemdeki sapmaların daha yavaş dengeye geldiğini ifade etmektedir.

\section{Ampirik Bulgular}

Veri seti ve ekonometrik yönteme ilişkin açıklanan bilgiler doğrultusunda analizin ilk aşaması olan birim kök testi yapılmış ve daha sonra ARDL sınır testine geçilmiştir. Çalışmada EViews 10.0 paket programından yararlanılmıştır.

\section{Tanımlayıcı istatistikler}

Çalışmada kullanılan 126 gözleme ait tanımlayıcı istatistikler Tablo 2'de gösterilmiştir.

Tablo 2.Tanımlayıcı İstatistikler

\begin{tabular}{|c|c|c|c|c|c|c|}
\hline & Ortalama & Ortanca & Maksimum & Minimum & Standart Sapma & Gözlem Say1s1 \\
\hline LNBIST & 7.446399 & 7.500768 & 7.937314 & 6.677121 & 0.302209 & 126 \\
\hline LNALIM & 22.66248 & 22.63518 & 23.53783 & 21.7065 & 0.297073 & 126 \\
& & & & & & 126 \\
\hline LNSATIS & 22.65303 & 22.63782 & 23.58678 & 21.67913 & 0.317379 & \\
\hline
\end{tabular}


Tablo 2 incelendiğinde LNBIST değişkenin ortalaması 7,446 iken standart sapmas1 0,302'dur. LNALIM değişkenin ortalaması 22,66 iken standart sapması 0,297'dir. LNSATIM değişkenin ise ortalaması 22,65 iken standart sapması 0,317'dir.

\section{Birim Kök Testi Sonuçları}

Çalışmada serilerin durağanlık düzeyleri Augmented Dickey-Fuller (ADF) ve PhillipsPerron (PP) birim kök testleri ile araştırılmıştır. ADF ve PP birim kök testlerine ait bulgular Tablo 3'te sunulmuştur.

Tablo 3. Birim Kök Test Sonuçları

\begin{tabular}{|l|c|c|c|c|c|c|c|c|}
\cline { 2 - 8 } \multicolumn{1}{c|}{} & \multicolumn{4}{c|}{ ADF } & \multicolumn{4}{c|}{ PP } \\
\cline { 2 - 9 } & \multicolumn{2}{|c|}{ Düzey Değeri } & \multicolumn{2}{c|}{ Birinci Fark } & \multicolumn{2}{c|}{ Düzey } & \multicolumn{2}{c|}{ Birinci Fark } \\
\cline { 2 - 9 } & Sabit & $\begin{array}{c}\text { Sabit ve } \\
\text { Trend }\end{array}$ & Sabit & $\begin{array}{c}\text { Sabit ve } \\
\text { Trend }\end{array}$ & Sabit & $\begin{array}{c}\text { Sabit ve } \\
\text { Trend }\end{array}$ & Sabit & $\begin{array}{c}\text { Sabit ve } \\
\text { Trend }\end{array}$ \\
\hline LNBIST & -0.802 & -3.080 & $-10.633 * * *$ & $-10.713 * * *$ & -0.646 & -3.103 & $-10.632 * * *$ & $-10.770 * * *$ \\
\hline LNALIM & $-2.720 *$ & $-4.495 * * *$ & $-17.199 * * *$ & $-17.126 * * *$ & $-4.424 * * *$ & $-7.085 * * *$ & $-19.483 * * *$ & $-19.405 * * *$ \\
\hline LNSATIS & $-2.583 *$ & $-4.363 * * *$ & $-16.989 * * *$ & $-16.921 * * *$ & $-4.101 * * *$ & $-6.846 * * *$ & $-18.797 * * *$ & $-18.727 * * *$ \\
\hline
\end{tabular}

Not: ADF testinde parantez içindeki değerler SCbilgi kriteri kullanılarak seçilen gecikme uzunluklarıdır ve maksimum gecikme uzunluğu 12 olarak alınmıştır. PP testinde optimal gecikme uzunluğu, Bartlett kernel (default) spectral estimation yöntemi ve Newey-West Bandwidth (automatic selection) kriterlerinden yararlanılmıştır. ${ }^{* * *},{ }^{* *}$ ve * sirasıyla $\% 1, \% 5$ ve $\% 10$ düzeyinde anlamlılı̆

Yapılan ADF ve PP birim kök sonuçlarına göre, LNALIM ve LNSATIS değişkenleri düzey değerlerinde durağan [I(0)], LNBIST değişkeni ise birinci farkta [I(1)] durağandır.

\section{ARDL Test Sonuçları}

ARDL yöntemi için gecikme uzunluğu seçiminde Akaike Bilgi Kriteri (AIC) temel alınmış olup bu kritere göre seçilen en uygun 20 modele ilişkin gecikme uzunluğu bilgileri Şekil 4'te sunulmaktadır.

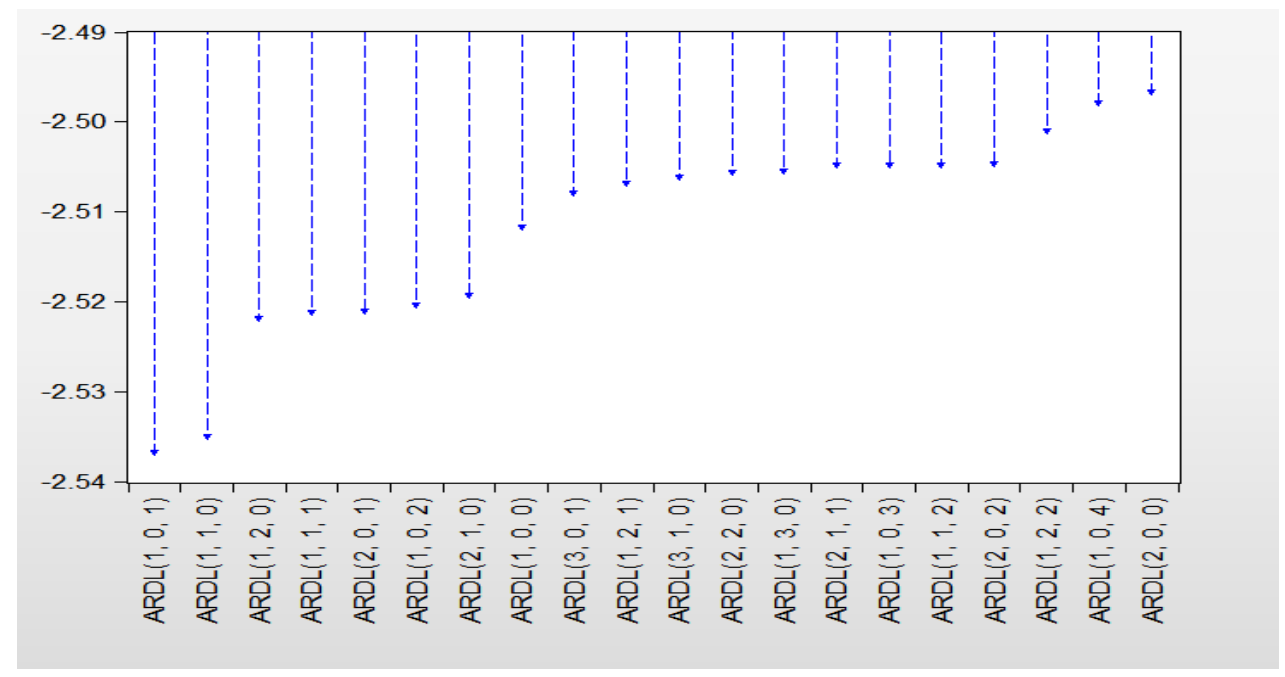

Şekil 4. AIC Bilgi Kriterine Göre Seçilmiş En Uygun 20 Model 


\section{Erkan USTAOĞLU}

Yabancı İşlemleri ile BIST100 Endeksi Arasındaki İlişki: ARDL Sınır Testi Yaklaşımı

Şekil 4 değerlendirildiğinde Akaike Bilgi Kriterine göre en uygun modelin ARDL $(1,0,1)$ modeli olduğu görülmektedir. Bu kapsamda, gerçekleştirilen analizlerde bu model temel alınmıştır.

Tablo 4.ARDL(1,0,1) Modeli F İstatistiği ve Kritik Değerler

\begin{tabular}{|c|c|c|c|c|}
\hline $\mathrm{k}$ & F İstatistiği & Önem Düzeyi & Alt Sinır & Üst Sınır \\
\hline \multirow{3}{*}{2} & \multirow{3}{*}{$33.036^{* * *}$} & $\% 10$ & 2.63 & 3.35 \\
\cline { 3 - 5 } & & $\% 5$ & 3.1 & 3.87 \\
\cline { 3 - 5 } & & $\% 1$ & 4.13 & 5 \\
\hline
\end{tabular}

Not:Maksimum gecikme uzunluğu 2 olarak alınmış ve optimal gecikme uzunlukları, Akaike bilgi kriterine göre belirlenmiştir. $\mathrm{k}$, açıklayıcı değişken sayısını ve *** ise \%1 düzeyinde anlamlılı̆̆ ifade etmektedir. Trend istatistiki olarak anlamsız olduğundan modele dahil edilmemiştir.

Tablo 4’te görüldüğü üzere, ARDL $(1,0,1)$ modeli için hesaplanan F istatistiği \%1 anlaml11ık düzeyinde kritik değerlerden büyük olduğundandeğişkenler arası eşbütünleşme ilişkisi bulunmadığı şeklinde kurulan $H_{0}$ hipotezi reddedilerek, değişkenler arası eşbütünleşme ilişkisi olduğu saptanmıştır. Uzun dönemli eşbütünleşme ilişkisi tespit edildikten sonra değişkenlere ait uzun ve kısa dönem ilişkilerin araştırılması aşamasına geçilebilir. ARDL $(1,0,1)$ modeli uzun ve kısa dönem katsayıları Tablo 5'te gösterilmiştir.

Tablo 5.ARDL(1,0,1) Modeli Kısa ve Uzun Dönem İlişkiler

\section{Uzun Dönem Katsayıları}

\begin{tabular}{|c|c|c|c|c|}
\hline Değişkenler & Katsayı & Standart Sapma & t-istatistiği & Olas1lik \\
\hline LNALIM & $15.586^{* *}$ & 7.179 & 2.171 & 0.031 \\
\hline LNSATIS & $-16.439 * *$ & 7.284 & -2.256 & 0.025 \\
\hline $\mathrm{C}$ & $26.460 * *$ & 10.685 & 2.476 & 0.014 \\
\hline \multicolumn{5}{|c|}{ Kısa Dönem Katsayıları (Hata Düzeltme Modeli) } \\
\hline$\Delta$ LNALIM & $0.816^{* * *}$ & 0.085 & 9.597 & 0.000 \\
\hline$\Delta$ LNSATIS & $-0.794 * * *$ & 0.074 & -10.662 & 0.000 \\
\hline KUKLA & 0.015 & 0.016 & 0.952 & 0.342 \\
\hline ecm(-1) Hata düzeltme terimi & $-0.052 * * *$ & 0.004 & -11.639 & 0.000 \\
\hline \multicolumn{5}{|l|}{ Tanısal Testler } \\
\hline$R^{2}$ & 0.526 & Otokorelasyon (LM) & & 0.914 \\
\hline Düzeltilmiş $R^{2}$ & 0.518 & Değişen Varyans (White) & & 0.113 \\
\hline F istatistiği (Olasılık) & $504.383(0.00)$ & Ramsey Reset Test & & 0.663 \\
\hline
\end{tabular}


Not: ${ }^{* * *}$ ve ** sırasıyla \%1 ile \%5 düzeyinde anlamlılığı ifade etmektedir. Trend istatistiki olarak anlamsız olduğundan modele dahil edilmemiştir.

Tablo 5'te $R^{2}(0.526)$ ve düzeltilmiş $R^{2}(0.518)$ olasılık değeri, bağımlı değişkenin bağımsız değişkenler tarafından açıklanma oranını, $F$ istatistiği olasılık değeri (0.00), modelimizin bir bütün olarak her düzeyde anlamlı olduğunu, otokorelasyon LM test olasıllk değeri (0.914), hata terimlerinin korelasyonlu olmadığını, değişen varyans White test olasılık değeri $(0,113)$ modelde hata terimlerinin varyansının sabit olduğunu ve Ramsey Reset Test olasılık değeri $(0,663)$ ise modelde model kurma hatasının olmadığını göstermektedir. Tablo 5'teki ARDL $(1,0,1)$ modeli uzun dönem ilişkileri incelendiğinde, LNALIM ve LNSATIM değişkenlerinin \%5 önem seviyesinde anlamlı olduğu tespit edilmiştir.Yabancı yatırımcının hisse senedi alımları (LNALIM) BIST100 endeksini (LNBIST) pozitif etkilerken, yabancı yatırımcıların yaptıkları hisse senedi satışları (LNSATIS) ise BIST100 endeksini negatif etkilemektedir. Bu sonuçlar Richards (2005) ve Gümüş’ün (2010) çalışmasını destekler niteliktedir. Tablo 5'teki sonuçlara göre yabancı yatırımcıların hisse senedi alımlarında meydana gelen \%1'lik bir artış BIST100 endeksinde uzun dönemde \%15,58'lik bir artışa sebep olurken, yabancı yatırımcıların hisse senedi satışlarındaki \%1'lik bir artış BIST100 endeksinde uzun dönemde \%16,43'lük bir azalmaya sebep olmaktadır. Bu sonuç Clark ve Berko (1997) ve Anayochukwu'nun (2012) çalışmalarını destekler niteliktedir. Clark ve Berko (1997), Meksika borsasında portföy yatırımlarındaki \%1'lik bir artışın hisse senedi fiyatlarında \%13'lük bir artışa sebep olduğunu tespit ederken, Anayochukwu (2012), Nijerya borsasında portföy yatırımlarındaki \%1'lik bir artışın borsa getirilerinde \%17'lik bir artışa neden olduğunu tespit etmiştir. Görüldüğü üzere BIST’te yabancı yatırımcıların alım etkisi, Meksika'ya oranla daha fazla iken, Nijerya'dan daha azdir.

Tablo 5'teki ARDL $(1,0,1)$ modeli kısa dönem ilişkileri incelendiğinde, ecm (-1) hata düzeltme terimi katsayısı - 0,052 olarak tespit edilmiştir. Hata düzeltme terimi katsayısı $\% 1$ önem seviyesinde anlamlıdır ve işareti beklendiği gibinegatiftir. Buna göre değişkenler arası uzun dönemli ilişki olduğu doğrulanmaktadır. Hata düzeltme terimi katsayısının -0,052 olması, bir şokun ya da olağanüstü bir etkinin gerçekleşmesi durumunda, kısa dönemdeki sapmaların bir sonraki ayda yaklaşık \%5,2 oranında düzeleceğini ve 1 yıl 7 ayda ise dengeye geleceğini ifade etmektedir.

Kısa dönemli katsayılar incelendiğinde $\triangle$ LNALIM ve $\triangle$ LNSATIM değişkenlerinin $\% 1$ önem seviyesinde anlamlı olduğu tespit edilmiştir. Yabancı yatırımcının hisse senedi alımları BIST100 endeksini kısa dönemde pozitif etkilerken, yabancı yatırımcıların yaptıkları hisse senedi satışları ise BIST100 endeksini kısa dönemde negatif etkilemektedir. Kısa dönemde yabancı yatırımcıların hisse senedi alımlarında meydana gelen \%1'lik bir artış BIST100 endeksinde $\% 0,816$ 'lık bir artışa sebep olurken, yabancı yatırımcıların hisse senedi satışlarındaki \%1'lik bir 


\section{Erkan USTAOĞLU}

\section{Yabancı İşlemleri ile BIST100 Endeksi Arasındaki İlişki: ARDL Sınır Testi Yaklaşımı}

artış iseBIST100 endeksinde \%0,794'lük bir azalmaya sebep olmaktadır.2017:4-2018:7 tarihleri arasındaki ortaya çıkan yapısal kırılmadan dolayı modele eklenen kukla değişken istatistiksel olarak anlamsız olmasına rağmen yapısal kırılmayı düzeltmektedir.

Tahmin edilen uzun dönem katsayılarının istikrarlı olup olmadığının araştırılması Brown, Durbin ve Evans (1975) tarafınca geliştirilen CUSUM ve CUSUM-Q testleri ile yapılmaktadır. Şekil 5'de CUSUM ve CUSUM-Q test sonuçları incelendiğinde, hata terimlerinin kritik değerleriçerisinde kalmış olduğu ve dolayısıyla katsayılarının istikrarlı oldukları anlaşılmaktadır.

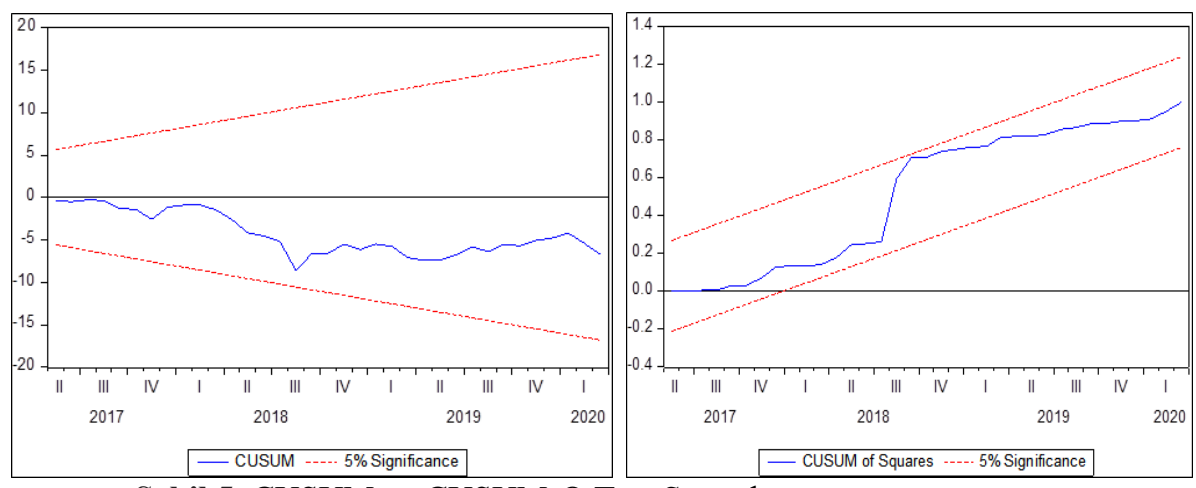

Şekil 5. CUSUM ve CUSUM-Q Test Sonuçları

\section{Sonuç}

Çalışmada 2009:09-2020:03 dönemi aylık veriler kullanılarak yabancı yatırımcıların BIST'te yaptıkları alım ve satım işlemleri ile BIST100 endeksi arasında olası kısa ve uzun dönemli ilişkileri, ARDL sınır testi ile araştırılmıştır. Yapılan analizler sonucunda yabancı yatırımcıların BIST'te yaptıkları hisse senedi alışları ve satışları ile BIST100 endeksi arasında uzun dönemli bir eşbütünleşme ilişkisiolduğu tespit edilmiştir. Yabancı yatırımcıların BIST’te yaptıkları hisse senedi alışları hem kısa dönemde hem de uzun dönemde BIST100 endeksini artırırken, yabancı yatırımcıların BIST'te yaptıkları hisse senedi satışları ise BIST100 endeksini azaltmaktadır.Yabancı yatırımcıların hisse senedi alımlarında meydana gelen \%1'lik bir artış BIST100 endeksinde uzun dönemde \%15,58'lik bir artışa sebep olurken, yabancı yatırımcıların hisse senedi satışlarındaki \%1'lik bir artış BIST100 endeksinde uzun dönemde \%16,43'lük bir azalmaya sebep olmaktadır. Görüldüğü üzere uzun dönemde BIST100 endeksi, yabanc1 yatırımcıların hisse senedi satış işlemlerinin etkisinden daha fazla etkilenmektedir. Kısa dönemde yabancı yatırımcıların hisse senedi alımlarında meydana gelen \%1'lik bir artış BIST100 endeksinde $\% 0,816$ ' lık bir artışa sebep olurken, yabancı yatırımcıların hisse senedi satışlarındaki \%1'lik bir artış ise BIST100 endeksinde \%0,794'lük bir azalmaya sebep olmaktadır.

Yabancıların BIST'te yaptıkları alım ve satım işlemlerinin BIST'teki toplam payı \%50 seviyelerine gelmiştir. Yabancıların BIST’teki paylarının bu denli yüksek olması yaptıkları işlemlerin borsa üzerindeki etkilerini de artırmaktadır. Yabancı yatırımcıların hisse senedi alımları arttıkça hisselerin fiyatları yükselmekte ve BIST100 endeksi de bu yükselişe paralel 
olarak artmaktadır. Yabancı yatırımcıların hisse senedi piyasasında yaptıkları işlemlerin BIST’e olan güçlü etkileri nedeniyle, hükümet yabancı yatırımcıları borsaya çekecek ve daha önemlisi onları BIST’te daha fazla tutacak politikalar üretmelidir.

İleride yapılacak çalışmalarda yabancı alım ve satım işlemlerinin BIST100 endeksi üzerinde bu önemli ve güçlü etkisi göz önüne alındığında, yabancı portföy yatırımlarının belirleyicilerinin neler olduğu, ülkeler arası belirleyici farklılıkların tespit edilmesi ve bu sayede politika yapıcıların uygulayacakları politikalar konusunda net önerilerde bulunmak önemli olacaktır.

\section{Kaynakça}

Akar, C. (2008). Net Yabancı İşlem Hacmi ile Hisse Senedi Getirileri Arasında Uzun Dönemli İlişki Var mıdır? Atatürk Üniversitesi İktisadi ve İdari Bilimler Dergisi, 22(2), 331-338.

Anayochukwu, O. B. (2012). The Impact of Stock Market Returns on Foreign Portfolio Investment in Nigeria. IOSR Journal of Business and Management, 2(4), 10-19.

Baklacı, H. F. (2009). İMKB'de Yabancı Yatırımcı İşlemleri ve Getiri Etkileşimi Üzerine Amprik Bir Çalışma. IMKB Dergisi, 11(42), 37-59.

Borsa İstanbul (2020). Borsa İstanbul Tarihsel ve Referans Veri Platformu. https://datastore.borsaistanbul.com/, (01.05.2020).

Brown, R. L., Durbin, J. ve Evans, J. M. (1975). Techniques for Testing the Constancy of Regression Relationships Over Time. Journal of the Royal Statistical Society: Series B (Methodological), 37(2), 149-163.

Clark, J. ve Berko, E. (1997). Foreign Investment Fluctuations and Emerging Market Stock Returns: The Case of Mexico. FRB of New York Staff Report (24).

Doğukanlı, H. ve Çetenak, H. (2008). Yabancı Portföy Yatırımları ile Hisse Senedi Getirisi Arasındaki İlişki: İMKB’de Sınama. Çukurova Üniversitesi İktisadi ve İdari Bilimler Fakültesi Dergisi, 12(2), 37-57.

Engle, R. F., ve Granger, C. W. (1987). Co-Integration and Error Correction: Representation, Estimation, and Testing. Econometrica:Journal of the Econometric Society, 251-276.

Feng, L., Lin, C. Y. ve Wang, C. (2017). Do Capital Flows Matter to Stock and House Prices? Evidence from China. Emerging Markets Finance and Trade, 53(10), 2215-2232.

Froot, K. A., O’Connell, P. G. J. ve Seasholes, M. S. (2001). The Portfolio Flows of International Investors. Journal of Financial Economics, 59(2), 151-193.

Garg, R. ve Dua, P. (2014). Foreign Portfolio Investment Flows to India: Determinants and Analysis. World Development, 59, 16-28.

Gültekin, M. ve Umutlu, M. (2016). Çeşitli Yatırımcı Gruplarının Hisse Senedi Net Alım İşlem Hacimleri ve Pazar Getirisi Arasındaki Etkileşim. Ege Akademik Bakış, 16(3)-451-460. 


\section{Erkan USTAOĞLU}

Yabanıı İşlemleri ile BIST100 Endeksi Arasındaki İlişki: ARDL Sınır Testi Yaklaşımı

Gümüş, G. K. (2010). Menkul Kıymet Piyasalarında Yabancı Yatırımcıların Etkisi: İstanbul Menkul Kıymetler Borsası. IMKB Dergisi, 11(44), 61-96.

Haider, M. A., Khan, M. A., Saddique, S. ve Hashmi, S. H. (2017). The Impact of Stock Market Performance on Foreign Portfolio Investment in China International Journal of Economics and Financial Issues The Impact of Stock Market Performance on Foreign Portfolio Investment in China. International Journal of Economics and Financial Issues, $7(2), 460-468$.

İbicioğlu, M. (2012). Yurtdışı Yerleşiklerin Hisse Senedi Piyasası Üzerindeki Etkisi: İmkb’de Endeks Bazında Uygulamalar. Ç.Ü. Sosyal Bilimler Enstitüsü Dergisi, 21(3), 41-54.

İskenderoğlu, Ö. ve Karadeniz, E. (2011). İMKB 100 Endeksi Getirisi ile Yabanc1 Portföy Yatırımları Arasındaki İlişkinin Analizi. Çağ Üniversitesi Sosyal Bilimler Dergisi, 8(1), 123-133.

Johansen, S. (1988). Statistical Analysis of Cointegrating Vectors. Journal of Economic Dynamics and Control, 12, 231-254.

Johansen, S. ve Juselius, K. (1990). Maximum Likelihood Estimation and Inference on Cointegration with Applications to The Demand for Money. Oxford Bulletin of Economics and Statistics, 52, 169-210.

Karataş, A., Dönmez, Ç. A. ve Kiraz, F. (2004). İstanbul Menkul Kıymetler Borsası'nda Yabancı Yatırımcıların Performans Analiz. İktisat İsletme ve Finans, 19(225), 95-104.

Kesik, A., Canakci, M. ve Tunali, H. (2016). Analyzing Impact of Non-Residents Holdings of Equities on BIST (Istanbul Stock Exchange) 100 Index. Journal of Economics, Finance and Accounting-(JEFA), 3(2), 166-166.

Narayan, P. K. ve Narayan, S. (2005). Estimating Income and Price Elasticities of Imports for Fiji in a Cointegration Framework. Economic Modelling, 22(3), 423-438.

Narayan, P. K. ve Smyth, R. (2006). What Determines Migration Flows From Low-Income to High-Income Countries? An Empirical Investigation of Fiji-U.S. Migration 1972-2001. Contemporary Economic Policy, 24(2), 332-342.

Okuyan, H. A. ve Erbaykal, E. (2011). İMKB'de Yabancı İşlem ve Hisse Senedi Getirileri İlişskisi. Doğuş Üniversitesi Dergisi, 12(2), 256-264.

Pesaran, M. H., Shin, Y. ve Smith, R. J. (2001). Bounds Testing Approaches to the Analysis of Level Relationships. Journal of Applied Econometrics, 16(3), 289-326.

Richards, A. (2005). Big Fish in Small Ponds: The Trading Behavior and Price Impact of Foreign Investors in Asian Emerging Equity Markets. Journal of Financial and Quantitative Analysis, 40(1), 1-27. 
Samarakoon, L. P. (2009). The Relation between Trades of Domestic and Foreign Investors and Stock Returns in Sri Lanka. Journal of International Financial Markets, Institutions and Money, 19(5), 850-861.

Şenol, Z. ve Koç, S. (2018). Yabancı Portföy Yatırımları, Borsa ve Makroekonomik Değişkenler Arası ilişkilerin VAR Yöntemiyle Analizi: Türkiye Örneği. Uluslararası İktisadi ve İdari Incelemeler Dergisi, (21), 1-20. 